\title{
A New Approach to the Cultural Heritage Documentation Process
}

\author{
Hugo Guimarães Sampaio ${ }^{1}$, Leonardo Luna de Melo Jorge ${ }^{2}$, \\ Rafael Mourão Fiuza ${ }^{3}$, Daniel Ribeiro Cardoso ${ }^{4}$ \\ 1,2,3,4 Universidade Federal do Ceará \\ 1,3\{hugoguimasampaio|rafaelmfiuza\}@gmail.com²leolmjl@arquitetura.ufc. \\ br4danielcardoso@ufc.br
}

Looking at the existing tools for preservation in patrimony, we perceive an over-appreciation in material heritage conservation over intangibles. Through the implementation of algorithmic documentation methodology, to obtain information that composes a certain cultural expression, this paper aims to present an attempt to expand the tools of documentation and registration of cultural heritage and also the applications of this approach for a language implementation with a propositional aspect.

Keywords: Cultural Heritage, Parametric Modeling, Process Documentation, Shape Grammar, Brazilian Design

\section{INTRODUCTION}

Looking at the existing tools for preservation in patrimony, we perceive an over-appreciation in material heritage conservation over intangibles. According to Fonseca (2003), for more than 70 years the expression "historical and artistic heritage" evoked among people the image of a set of ancient monuments that we must preserve, either because they constitute exceptional works of art or because they have been the scenery of remarkable events, referred to historians' documents and narratives.

Heritage, by the 1988 Federal Constitution of Brazil (2016), is defined as "material and immaterial nature [...] bearers of reference to identity, to action to the memory of the different formative groups of Brazilian society." Therefore, collective cultural expressions also represent the nation's imaginary and deserve instruments of conservation.

According to Fonseca (2003: 69p), heritage is not only buildings and objects deposited in museums, written and audiovisual documents, kept in libraries and archives. Interpretations and institutions, as well as legends, myths, rites, knowledge, and techniques, can be considered as examples of intangible heritage. In many cases, the patrimony physical protection is unfeasible, even though this is not the most appropriate logic of preservation. What matters is to ensure the reproduction process continuity, preserving and guarding the ways of doing and respect for values such as the dynamics of doing and the adequacy of useful technique, for example.

The distance from practices and contexts sometimes does not take into account that all material patrimony is a reflection of intangible cultures, which use matter as way to support expression. Therefore, isolated objects are not enough to preserve cultural praxis, because they represent a sample of a shared repertory of experiences that manifests itself as liv- 
ing language changing in time, carrying characteristics of each people identities.

The focus on intangible heritage seeks to preserve expressions which are presented in material instances but have their power in their processes, actions, and ways of doing. Fonseca (2003) affirms that the most authentic values of identity are discovered from goods coming mainly from the popular making, which are not considered cultural goods because they are inserted in the living dynamics of daily life. So, if the heritage has material bundling, its language formalization can bring new understandings about its cultural identity.

\section{HYPOTHESIS}

Would be possible to expand forms of documentation and recording of material patrimony so it could capture nuances of its immaterial counterpart and cultural changes in time? Could heritage documentation expand design practices? Also, could parametric modeling tools help in this expansion? According to Fonseca (2003) this process is not only possible but necessary:

Some considerations must be made to help map out this new and broader Brazilian cultural heritage representation, and to draw up methods that contribute to the approximation of the cultural heritage produced in the country, especially in the issue of intangible heritage. The process of re-reading the question about cultural heritage is not exhausted at the conceptual level. Instead, it requires the involvement of new agents and the search for new instruments for preservation and promotion.

Faced with this is the consolidation of computational tools, in which it is possible to capture not only the object but also the logic that constitutes it. Through an algorithmic description of the objects it is possible to characterize them as a sequence of operations of the raw materials, and thus to approach the documentation of the process. Thus, the application of parametric tools for memory preservation seeks to register the forming process, since this looks an all-embracing approach in comparison to the sim- ple documentation, sometimes sacralized, of individual objects.

This immaterial process layer is present in the logical description of the steps in algorithm coding since the sequential aspect of this type of approach requires that all the forms and the processes be clearly described by geometric and mathematical tools. Therefore, according to the documentary objectives of the present research, non-parametric modeling proved to be insufficient, since its approaches considered the object as a model and not as a set of rules and processes, a limitation that is no longer found in parametric modeling. That is when describing in just one algorithm the logical chain is possible to reach the various models, pointing out that such an approach is appropriate for documentation of local cultures because it represents a large amount of information, extrapolating the possibilities of cataloging models.

\section{OBJECTIVES}

This paper aims to present an attempt to expand the tools of documentation and registration of cultural heritage. As a case study, the parametric modeling tool was applied as a means of documenting two typical Brazilian cultural expressions, located in the coastal municipality of Icapuí in the state of Ceará, Brazil: the houses of fishermen and their boats, both built by local hands of naval carpenters and builders, see figure 1.

\section{METHOD}

Being an inferential method (Cardoso 2010), the first moment, in the field, is the survey of a large number of houses and boats, searching for their recurrences and identifying the main elements of their grammars, as well as an interview with the masters who mastered these ways of doing. Manual and photogrammetric surveys were used for the research. (Photogrammetry Figure) With these results in hand, it was possible to apply inductive analysis that clarified the patterns and stages of production of the two objects. To formalize the language in dia- 
Figure 1

Typical houses and boats of Icapuí city
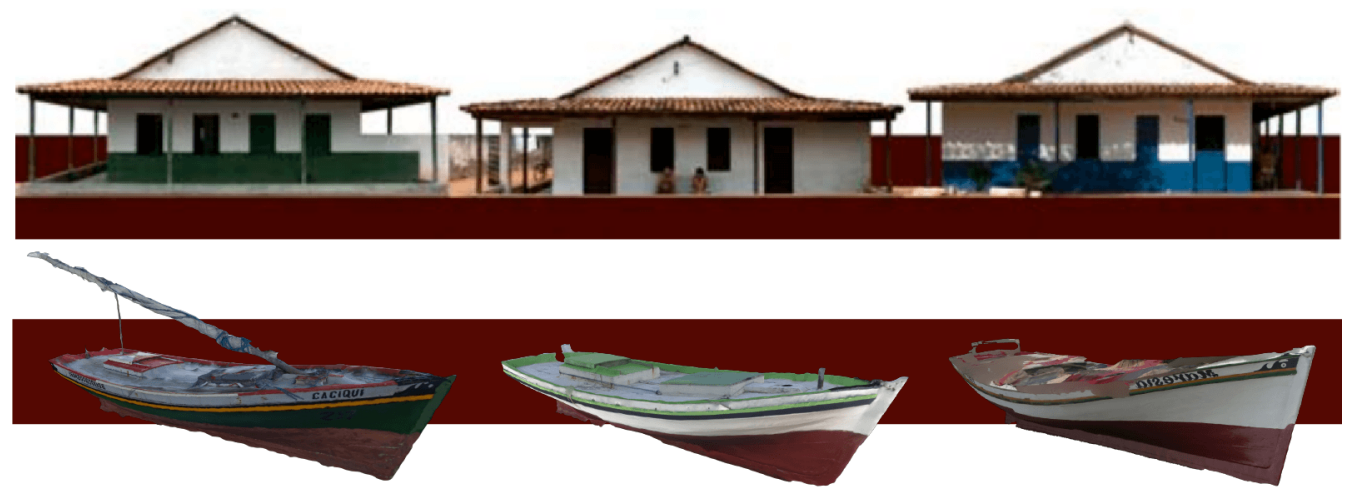

gram representation, the process was described, exposing the technical limitations, formal preferences, ways of thinking, technological advances in manufacturing and nuances of their ways of life. The process was coded for algorithmic representations on two parametric platforms: Python for houses and Rhino+Grasshopper for boats.

\section{RESULTS}

Throughout the implementation of algorithmic documentation methodology, to obtain information that composes a certain cultural expression, it is necessary to compare similar individuals, instantiated materially as a representation of the abstraction that is their language. The symbolic dimension of a cultural expression needs a material substrate so that through it it is possible to make abstraction into intelligible phenomena. Therefore, in order to access parts of the ontology either from boats or houses, it was necessary to notice in the samples which elements remained between objects, and the composition of such recurrences pointed to the formalization of the two languages.

Shape grammar was chosen as formalization method, since analytic grammar benefits from the extensive collection of data from individuals, as evidenced by Celani (2006): "analytic grammar consists, first of all, in choosing a set of works [...] which, at first sight, bear some resemblance to one another. "

Once the processes that result in the objects have been clarified and the information described by the masters in the interviews has been explained, algorithms have been implemented capable of sequentially constructing the objects, besides their codifications have variations that produce coherent cutouts with the studied ontologies. Processes were documented, not just process results from individuals.

The logic synthesized in the study of houses was implemented in Python and brings with it the different stages of zoning composition of the spaces, as well as the geometric constraints imposed by the proportions found in the sample field of analysis. Initially, the shape and proportions of the plant are retracted forming the porch and the living zone, which in turn was decomposed in the other spaces of the program. The relationship between the environments is governed by the topology also extracted from the samples, and the organization of such information in the form of graphs allows to implement not only formal but also programmatic aspects, see figure 2 .

The boats were implemented in Rhino + Grasshopper, demonstrating the step-by-step con- 
Figure 2

Diagram of the house

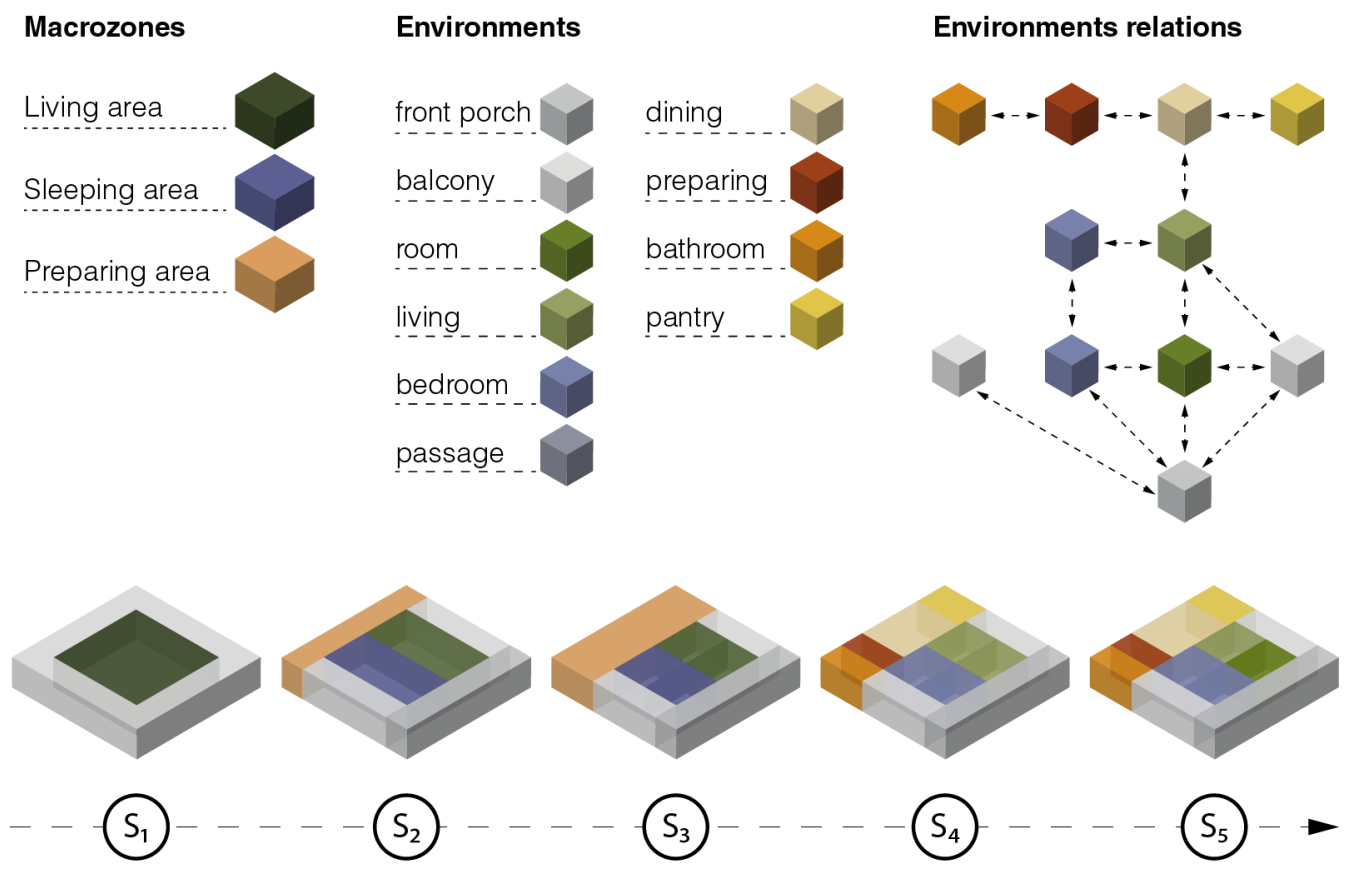

struction of a boat, allowing the variations described by the masters. The layout of the keel and master caves, see figure 3, proved to be the most important since they determine the proportions of the boats. In addition, the colors of the hull, the shape and position of the sail and the shape and position of the talhamar and cadaste help to characterize and differentiate the boats of Icapuí from other families of boats. The more trained look of the masters carpenters and residents of the region of Icapuí, can identify, through different characteristics, who built each object, whether house or boat.

The models of the boats and the houses, gen- erated by the algorithms, were printed in $3 D$ and presented to these masters carpenters and residents for validation of the objects while form and process and possible identification of the constructor of the model. See figure 4.

\section{DISCUSSION}

The parametric documentary approach contributes to cultural heritage since the algorithmic description is capable of carrying with it more information pertaining to the ontology of a clipping of individuals than its morphology and materiality. The need to sequentially describe the process, store information 
Figure 3

Diagram of the boat
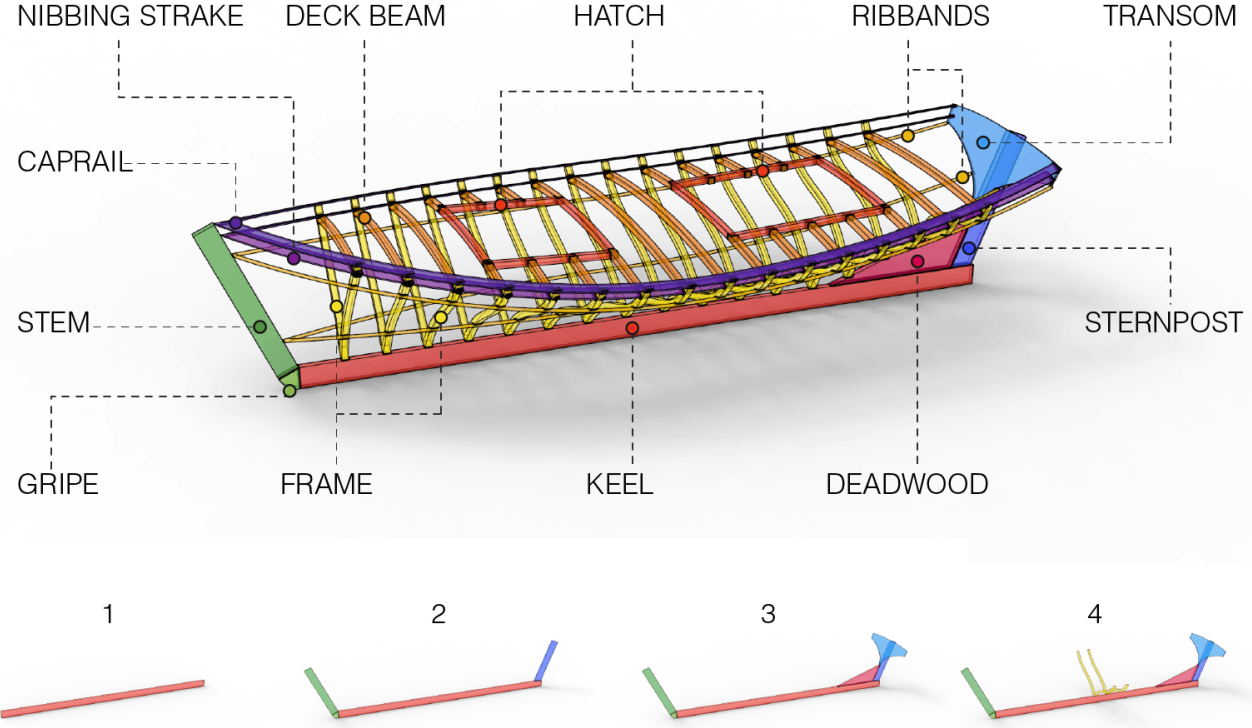

5

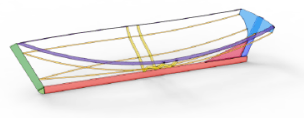

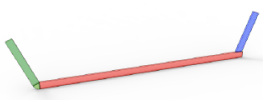

6

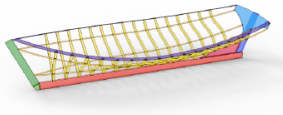

3

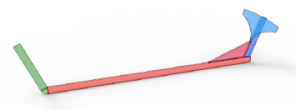

7

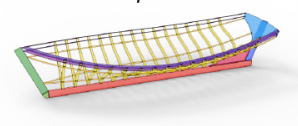

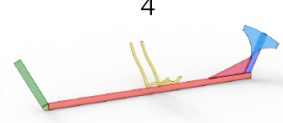

8

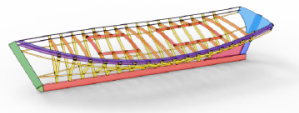

regarding the techniques and actions employed, as well as the relationships between the parts of the object. Thus, the present work proposes an approach of the formalization of languages, that structured in a computational tool, approaches the cultural complexity of the historical cuts. In this sense, digital processes and computational thinking often act as an accelerating tool for the creation and optimization of projects aimed at preserving and preserving a memory, since many of the processes used (photographs, videos, written documents ) are sometimes ineffective at documenting the procedural nature of artifacts.

According to Fonseca (2007), today, we face the expansion of the notion of cultural heritage, and, consequently, the challenge of preserving processes. We know that it is not possible to preserve them without the participation of producers and all the people involved in their production, consumption and transmission dynamics. We also know that it is not possible to preserve them by simply using the power of laws and the refinement of techniques, and we also know that the preservation of their physical support is not sufficient for their safeguarding or for the full transmission of their memory.

This approach, as it was done in view of the se- 
quence of design and constructive choices of objects, is a way of expanding heritage documentation, complementing other forms of registration, and evidencing the design choices of masters. This evidence is also useful when noted the possibility of making the choices and reimagining them in new projects, bringing the choices of the past closer to the act of designing today. As well as the biological concept of memory described by Aloísio Magalhães (1985):

When one speaks of memory in a figurative sense, when one lends the idea of memory to any one fact, there is usually a tendency to become something like" putting together "or" holding "something," holding back. " And this seems to me unsatisfactory, I prefer the biological concept of memory: to guard, to retain, and then to mobilize and to return.

Nowadays, the new masters do not build only sailing boats, but motorboats. They use the same language but now adapted to the new technologies available. This caused the proportions of the boats to change, leaving them wider and steadier, but slower, since the job of moving the boat is the engine, see
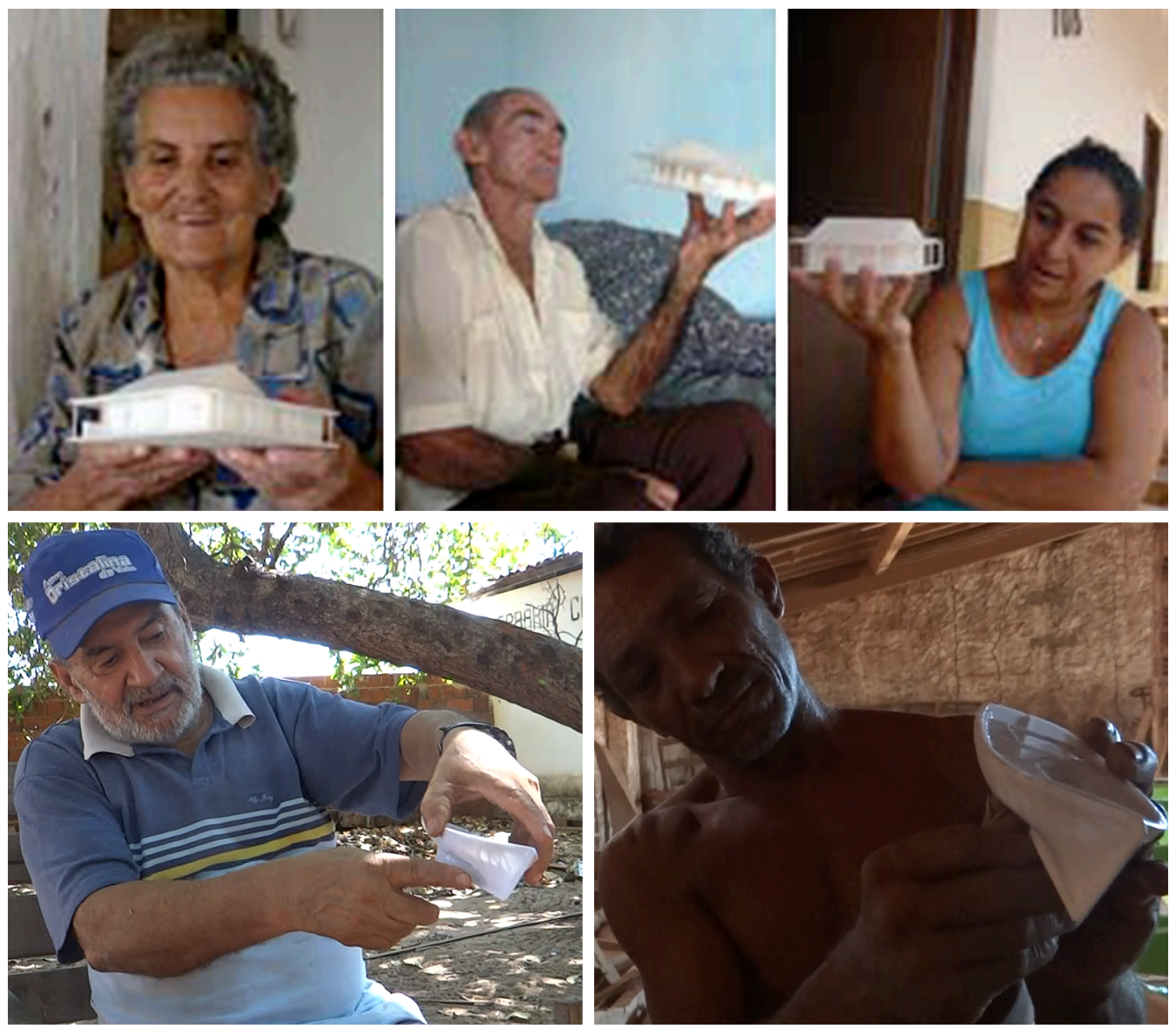

Figure 4

Residents and builders with the 3D printed model 
Figure 5

Two models of boats generated

Figure 6

Beach house by Daniel Cardoso
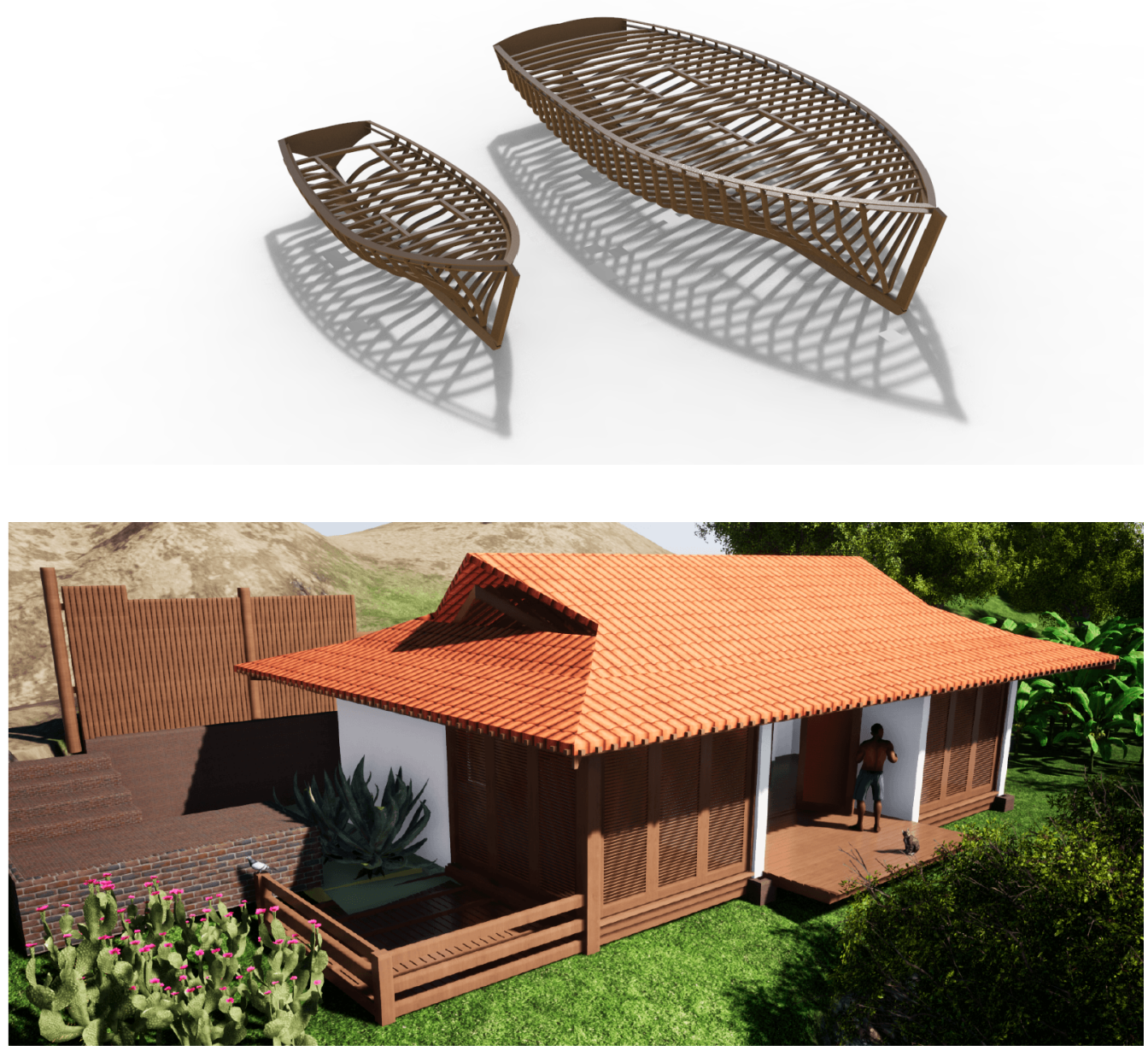
figure 5 .

Another development of the language one of the applications developed by Daniel Cardoso was the adaptation of the traditional language of the houses of the fishermen in a new program. Its beach house uses the same proportions and language of cover, however creating a free modern plan where the spaces are arranged without partitions. See figure 6.

According to Magalhães apud Anastassakis (2012) A culture is evaluated in time and is inserted in the historical process not only by the diversity of the elements that constitute it, or by the number of representations that emerge from it, but especially by its continuity. This continuity involves changes and changes in an open and flexible process, of constant feedback, which guarantees a culture its survival.

In addition, as a result of this line of research, new applications of this approach to language implementation are being developed at the Federal University of Ceará, now with a propositional aspect. The architectural programs of the popular house, the popular market, and new models of boats are being developed.

\section{REFERENCES}

ANASTASSAKIS, Z 2012, 'Vinculações entre Design e Cultura no Brasil: a outra vertente de LINA BO BARDI e ALOÍSIO MAGALHÃES', in CAMARGO, PO et al (eds) 2012, Design e/é Patrimônio, G3 Gráfica e Editora Me, Rio de Janeiro

Brasil, [Constituição (1988)] (eds) 2016, Constituição da República Federativa do Brasil: texto constitucional promulgado em 5 de outubro de 1988, com as alterações determinadas pelas Emendas Constitucionais de Revisão nos 1 a 6/94, pelas Emendas Constitucionais nos 1/92 a 91/2016 e pelo Decreto Legislativo no 186/2008., Senado Federal, Coordenação de Edições Técnicas, Brasília

CARDOSO, DR 2010, Desenho de uma poiesis, Expressão Gráfica e Editora, Fortaleza

CARDOSO, DR, BRASIL, AC and BEZERRA, RF 2007 'Casas de Icapuí, V Seminário Arquitectura da Terra em Portugal 2007, Aveiro, pp. 1-8

CELANI, Gabriela et al 2006, 'A Gramática da Forma como metodologia de análise e síntese em arquitetura',
Conexão- Comunicação e Cultura, 5(10), pp. 180-197

FIUZA, RM, JORGE, LLM, SAMPAIO, HG and CARDOSO, DR 2018 'Brazilian Design: Parametric modeling as memory of vernacular artifacts', Sigradi 2018, São Paulo, pp. 199-204

FONSECA, MCL 2003, 'Para além da pedra e cal: por uma concepção ampla de patrimônio cultural', in ABREU, R and CHAGAS, M (eds) 2003, Memória e patrimônio. Ensaios contemporâneos, DP\&A, Rio de Janeiro

FONSECA, MCL 2007, 'Patrimônio Cultural: por uma abordagem integrada (Considerações sobre materialidade e imaterialidade na prática da preservação),' in RJ, Copedoc/IPHAN (eds) 2007, Cadernos de Estudo do PEP: contribuições dos palestrantes da 1a oficina de PEP, IPHAN, pp. 69-73

GARGARO, S, CIGOLA, M, GALLOZZI, A and FIORAVANTI, A 2018 'Cultural Heritage Knowledge Context - A model based on Collaborative Cultural approach', Proceedings of the 36th eCAADe Conference, Lodz, Poland, pp. 205-214

JORGE, LLM, FIUZA, RM and CARDOSO, DR 2017 'Moderno Paramétrico: Para Além da Fenomenologia na Arquitetura', Sigradi 2017, São Paulo, pp. 559-564

MAGALHÃES, A 1985, E triunfo?, Nova Fronteira/Fundação Nacional Pró-Memória, Rio de Janeiro/Brasília 